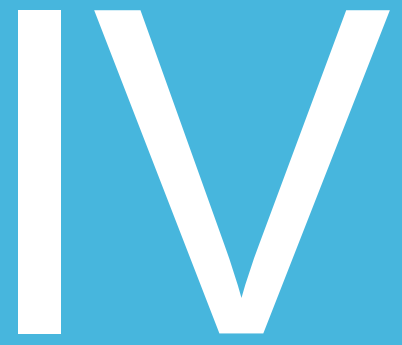

\title{
ENTRE EL MITO Y EL MATE: COMPETENCIAS MÉDICAS Y POSMODERNIDAD
}

\section{Between myth and mate: medical skills and postmodernism}

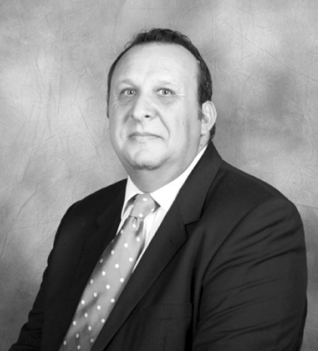

\section{Víctor M. Armenteros}

Licenciado en Teología por el Colegio Adventista del Plata (Argentina) y licenciado en Filología Semítica, con especialidad en hebreo y arameo, por la Universidad Central de Barcelona (España). Hizo cursos doctorales en Lengua y Cultura Hebraico-Española, con especialidad en Literatura Rabínica Tannaítica, por la Universidad de Granada (España).

Doctor en Filología Semítica por la Universidad de Granada. Traductor del proyecto de la Biblia Interconfesional de las Sociedades Bíblicas y la Casa de la Biblia. Escritor prolífico y ponente internacional. Actualmente se desempeña como Vicerrector Académico de la Universidad Adventista del Plata. 


\section{Resumen}

A través de los diferentes momentos de la historia, la visualización del médico ha ido variando. En la actualidad, el choque entre la modernidad sólida y la modernidad líquida (posmodernidad) continúa alterando conceptos y valoraciones. Este artículo propone una reflexión, desde una plataforma dialógica, de las cuestiones que se plantean en el momento de la elaboración de competencias médicas frente al impacto de la posmodernidad.

Palabras clave: Competencias médicas, postmodernidad, medicina, ética.

\section{Abstract}

Through the different moments of history display method has changed. Today the clash between modernity and modernity solid liquid (Postmodernism) continues altering concepts and valuations. This paper reflects from a dialogic platform of the issues raised at the time of the development of medical expertise from the impact of postmodernism.

Keywords: Medical expertise, postmodernism, medicine, ethics. 


\section{Introducción}

Puede que nuestra historia se sintetice en una taberna del Mediterráneo al declinar la tarde. Junto al ruido, seco y decidido, de una ficha de dominó impactando sobre una mesa de mármol, las conversaciones se intercalan con vigorosa creatividad y pasión. Las tres figuras más relevantes de aquellos pueblos encalados y siempre sesteantes se concretan en los oficios mitificados: el médico, el maestro y el clérigo. Al primero le compete lo relativo al "ser", al segundo lo del "llegar a ser" y al tercero lo del "más allá del ser". Espacios respetados pero no estancos. Hasta el siglo XVIII se podía decir que el doctor apenas si podía diagnosticar, en algunas ocasiones salvar y, normalmente, consolar. El "ser" era apenas esbozado y se suplía la carencia de información con empatía y sensibilidad. Se proponía el "llegar a ser" con multitud de consejos y se coqueteaba con el "más allá del ser" fortaleciendo la fe o la esperanza.

La imagen, desde los ojos del paciente, se refleja, sin lugar a dudas, en la estampa que presenta Eduarda Mansilla en "El Médico de San Luis":

He visto la muerte en casi todas sus formas, he contemplado la agonía del hombre robusto y vigoroso que va cediendo por grados sus derechos a la muerte, he sentido helarse la sangre en las venas del anciano en el último tercio de su vida, he visto al tierno niño sonrosado y risueño en los brazos de su madre, pero nunca he experimentado lo que viví en aquella media hora. Agueda abrió los ojos y fijándolos en mí sin asombro, me dijo con voz trémula y apagada: Bien sabía que Ud. había de venir, ¿̇y la chica? Ha salido un momento, yo la he mandado, no puede tardar. ¿Cómo se siente Ud., hija mía? Mejor, señor, ya esto es hecho, me voy sin remedio. Cuídeme mucho a la chica, dígaselo a la señora, y que Dios se lo pague. Tengo mucha sed, allí en el rincón hay un jarro con agua, hágame el favor. Le alcancé el jarro, bebió con avidez, y enseguida cerró de nuevo los ojos. Poco después entró el cura seguido de Jorge, la enferma al verle hizo la señal de la cruz, me miró por última vez y cayó en un sopor precursor de la muerte. Mi misión había concluido, apenas le quedaban algunos instantes. El sacerdote le puso la extrema unción y se arrodilló cerca de la cama. Amigo mío, dije a Gifford, tengo otros enfermos que visitar, el día empieza mal, pero mi deber es disputar su presa a la muerte, mientras haya esperanza. Ruego a Ud. se quede aquí hasta la llegada de mi mujer. Pronto vuelvo.

Una aproximación sencilla a la wirkungsgesichte de este texto nos propone la imagen del médico desde la mirada femenina, rural, de espacios no tecnificados en la que destaca cierto paternalismo, proximidad emocional 
y presencial, disposición y alto nivel de responsabilidad. Le competía proteger, preocuparse e, indudablemente, estar. La llegada del médico o su misma presencia era señal de esperanza. "Pronto vuelvo" expresa el intenso vínculo de persona a persona.

Aquel médico abandonó el monóculo por las lentes, el microscopio óptico por el electrónico. Con el premio Nobel de Medicina en 1974 a Albert Claude, George Palade y Christian de Duve se galardonaba la instrumentalización de la mirada celular. El "ser" no solo era un conjunto de órganos o tejidos sino de cien billones de células. De igual forma aconteció con la observación de la herencia, de las veintiún mil plantas de Gregor Mendel a los experimentos de Alfred Hershey y Martha Chase con el ADN, hay un salto exponencial. El Proyecto Genoma Humano se adentró en el mapeo del ser desde su mínima expresión. Las enfermedades más usuales de finales del XIX y principios del XX fueron en regresión gracias a los avances de la Medicina. Sífilis, malaria, polio, tuberculosis o fiebres reumáticas eran marca de normalidad en el siglo pasado y se hallan en franco retroceso gracias a antibióticos específicos, entre ellos estreptomicina y penicilina.

La Medicina era uno de los bastiones de la modernidad, de los resultados de la ciencia como vaca sagrada. La magnificación de los posibles logros modeló progresivamente el perfil de muchos profesionales del área. Eran tiempos de horizontes ilimitados, de alzarse sobre hombros de gigantes y se cayó en la tentación de la distancia, sea por especialización o por el incremento de la diglosia diastrática, y de cierto narcisismo que resultaron en una admiración cuasichamánica para con el cuerpo médico.

Pero llegó la posmodernidad.

Nada parecía alterado con la incorporación del postarte de la realidad del desencanto. Sin embargo, la naturaleza de la postestética había fragmentado la vida hasta el instante sin memoria. Como dirá Díaz (2009, p. 48):

... la redundancia informática y la comunicación de masas nos ha arrojado al vértigo de la instantaneidad. Ya no es posible definir al hombre como una identidad homogénea sino más bien como metamorfosis. Las ciencias, el arte y las formas de vida se han fragmentado en la pluralidad, la discontinuidad y la dispersión. La moda ha ocupado el lugar de forma de vida total. Es decir, las formas de vida que las vanguardias modernistas pronosticaban para el arte. Gilles Lipovetsky considera que la moda, un invento moderno en la posmodernidad, ha llegado a convertirse en un principio organizativo de la vida. La moda, que comenzó siendo un principio de diferenciación de clases y de imperio de lo novedoso en los inicios de la modernidad, hoy abarca todos los ámbitos del quehacer humano. 
Más preocupante resultaba la posética. La relativización de los universales y de sus fundamentos, en combinación con la filosofía del consumo, ha generado una crisis de moralidad que se aproxima más al contexto que a la necesidad. En palabras de Díaz (2009, p. 73):

La ética moderna ha sido fagocitada por el marketing. Este cambio de dispositivo ético-social se está generando a partir de la mitad del siglo XX. Denomino 'posética' a esta nueva relación entre el hombre y los valores. Los elementos éticos formales siguen siendo los mismos. Se trata de los valores, de lo que está bien y de lo que está mal. Sin embargo, hay un cambio fundamental: el tipo de interrogantes que el sujeto se plantea respecto de su acción moral. La modernidad se preguntaba acerca de lo necesario (categórico). En cambio, la posmodernidad se pregunta acerca de lo conveniente (hipotético).

Los análisis de Karl Popper y de Thomas Kuhn habían desacralizado la investigación científica. El impacto de Imre Lakatos y Paul Feyerabend desataba la realidad de la posciencia. Parecía que la Medicina se hallaba ausente de este macrodebate cuando surgen nuevos virus o agentes infecciosos como los priones. La llegada a finales de los setenta del SIDA no podía imaginar el desarrollo de tal enfermedad. Decenas de millones de personas padecen hoy día la infección por HIV. La fiebre del Nilo, el dengue, el Ébola, el síndrome respiratorio agudo severo (SRAS), la enfermedad de Lyme, la encefalopatía espongiforme bovina, la enfermedad pulmonar obstructiva crónica (EPOC) conforman algunos de los ejemplos de nuevas enfermedades que menoscabaron a la Ciencia como panacea. Pero, sin lugar a dudas, es el cáncer el que más ha desacreditado a la Medicina que se halla indefensa ante su incremento incluso en países desarrollados. La realidad idílica propuesta por la ciencia de la modernidad no responde a sus expectativas. Como dirá García (2011):

La injusta y dispar atención sanitaria, con grandes segmentos de la población mundial sin acceso a los cuidados básicos. Mientras el $90 \%$ de la carga de enfermedad gravita sobre los países en desarrollo, estos países tienen acceso solamente al $10 \%$ de los recursos sanitarios. Una quinta parte de la humanidad no tiene acceso a servicios de salud adecuados y la mitad no puede disponer de fármacos esenciales. A pesar del teórico principio de igualdad en el derecho a la salud, las desigualdades se amplían ante nosotros tanto en el mundo en desarrollo, donde la justicia exige un cambio radical del panorama, como en el desarrollado, donde la población demanda cada día mayores prestaciones. La rápida deterioración y degradación del medio ambiente constituye, además de tener otras múltiples implicaciones, una fuente de 
Víctor M. Armenteros

problemas sanitarios. La calidad del agua, crítica para el mantenimiento de las condiciones de salud, la polución atmosférica con su contribución creciente a las enfermedades respiratorias y al cáncer o el calentamiento global que transporta las enfermedades tropicales a latitudes nórdicas, son algunos ejemplos bien conocidos.

La incapacidad de dominar las grandes epidemias como el SIDA, la malaria, la tuberculosis, junto al impacto creciente de catástrofes, guerras y desastres naturales que los medios de comunicación se encargan de darnos a conocer con detalle, acentúan la demanda de un mayor desarrollo de los conocimientos y, sobre todo, de los recursos destinados a la salud.

Al lado de estos y otros problemas sanitarios, existe un problema ético más profundo. Actualmente se considera correcto y avanzado asumir que la vida de ciertos seres humanos carece de sentido y, bajo capa de una presunta compasión o invocando unos derechos al propio cuerpo o al propio bienestar, se promueve su eliminación para comodidad y beneficio de los más fuertes. Tanto la ética como el derecho médicos tienen ante sí un panorama inmenso para la reflexión y la acción.

El proyecto de la modernidad parece haberse resquebrajado. La posmodernidad se ha instalado para desestabilizar las estructuras precedentes (oficio, familia tradicional, funciones de género, colectivos, etc.) y atemorizar al individuo. La aldea global se está convirtiendo en la célula global. Y este proceso afecta, inevitablemente, el desempeño de la medicina. Las reacciones ante tal evolución pueden clasificarse en tres:

a) Nostálgicas

Buscan en la premodernidad modelos a imitar. De ahí que se rescaten prácticas médicas milenarias y se cuestione la medicina científica. Los modelos de medicina alternativa, curanderismo y chamanismo surgen con el vigor de propuestas equiparables a la medicina científica (Panadero, 2006 pp. 351-363).

\section{b) Desencantadas}

Participan de la esencia más íntima de la posmodernidad y derivan en una crisis de inteligibilidad (Martínez, 2011. pp. 59-97). Como desgrana a la perfección Vélez (2009, p.84):

Es pues la postmodernidad, una época de desencanto, se pasa de la producción al consumo, desaparecen las grandes figuras carismáticas y surgen pequeñas figuras y líderes que perduran muy poco; la defensa 
del medioambiente se mezcla con la compulsión al consumo; el dominio de las masas y el "marketing" dominan todos los aspectos de la vida en los centros del poder, no importa si es religión, política o producción de bienes. No importa el contenido del mensaje que se envía sino la forma cómo se envía; desaparece la ideología y ésta es reemplazada por la imagen. Los medios de masas se convierten en transmisores de la verdad. La información en sí no importa, lo importante es el entretenimiento. Se pierde la intimidad y la vida del otro se convierte en show. Se desacraliza la política y desmitifica a los líderes. No importa el pasado, no importa el futuro, es la perenne búsqueda de lo inmediato. Se vuelve a lo místico y se busca una revolución interior, pero al mismo tiempo hay un culto exagerado al cuerpo. Se pierde la fe y no se cree en la razón, pero se rinde un culto que cae en veneración a la tecnología sin entender sus bases, como si éstas no importasen. Desaparece el idealismo. Se desprecia la autosuperación, no se valora el esfuerzo. Se tiene un concepto personal sobre la iglesia y sobre Dios. Lo importante no son los hechos sino la interpretación de esos hechos; la certeza de un hecho no es más que eso, una verdad relativamente interpretada. Todo es relativo, nada es absoluto.

c) Innovadoras

Fuertemente vinculadas con Paulo Freire y Jürgen Habermas proponen un marco de comunicación que genere transformaciones sociales, es lo que se denomina modernidad dialógica. ${ }^{1}$ La ambigüedad en la que se desenvuelve la posmodernidad precisa de la expresión fluida entre pares para hallar alternativas. El recurso de los estudiantes en dicho proceso de crecimiento comunicativo producirá, en el discurso de Fielding (Journal of Educational Change, 2001 pp. 123-141; British Educational Research Journal, 2004 pp. 295-311) un auténtico cambio social.

En esta última plataforma se situará este artículo. Analizando los impactos sociales que ha generado la posmodernidad propondremos, a modo de tertulia dialógica esbozada, el catalizador de reflexiones sobre el devenir de la formación en Medicina y el crecimiento pedagógico de los docentes del área.

\footnotetext{
${ }^{1}$ En la definición de Carmen Elboj Saso y Jesús Gómez Alonso en “El giro dialógico de las ciencias sociales: hacia la comprensión de una metodología dialógica", Acciones e investigaciones sociales 12 (2001): 81: "La investigación científica basada en el enfoque dialógico permite alcanzar diversos objetivos. Por una parte, hace posible el desarrollo de una teoría interpretativa y de análisis de la realidad. Por otra parte, constituye una profundización en una metodología crítica e innovadora. Y, por último, permite superar una de las dualidades más habituales en las ciencias sociales, es decir, la relación sujeto/objeto. Constituye, pues, una manera de incorporar las opiniones y los intereses de los participantes, normalmente excluidos de los procesos de legitimación científica".
} 
Víctor M. Armenteros

Además, se planteará desde el modelo de competencias. Como indican González et al (2008, pp. 162-165):

Entre los desafíos que hoy enfrentan las Escuelas y Facultades de Medicina, con respecto a la formación y capacitación de profesores, se encuentran aquellos que demandan una visión del desempeño docente más coherente con una visión integral, como es el caso del modelo de competencias aquí presentado. La concepción rutinaria y tradicional del profesor como un "expositor de clase", donde éste es el principal actor del proceso de enseñanza-aprendizaje, constituye para las necesidades actuales de formación de médicos y de los profesores correspondientes, un modelo atípico e insuficiente, que reclama una participación central, comprometida y dinámica del estudiante en su proceso de formación profesional.

Matizada la pirámide de Miller y, considerando el modelo de Cambridge de competencias y desempeño (Figura 1), recurriremos a las influencias que recibe el individuo para fortalecer la formación de éste.

Figura 1

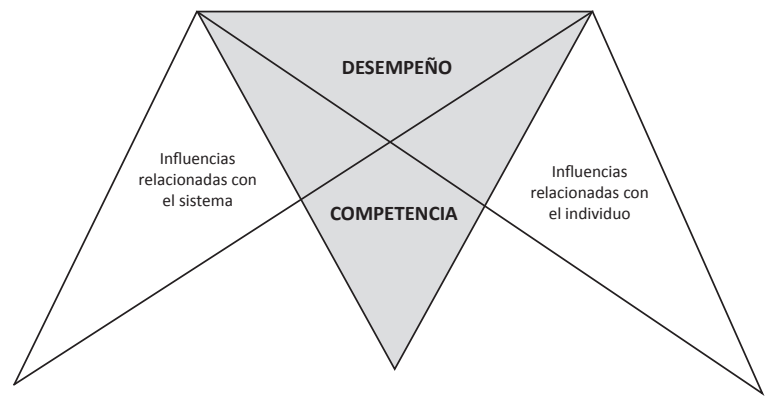

El paciente demanda del médico algo más que el diagnóstico, como diría Gregory Bateson: "The map is not the territory and the name is not the thing named". Es quizá por esa razón que tal vez debiéramos volver a una propuesta más íntegra del actor de la medicina (Figura 2): el ser (superando el análisis del objeto y procurando la comprensión de la persona), el llegar a ser (siendo consciente de la influencia implícita de la función y de la responsabilidad formativa derivada de ella) y del más allá del ser (reconociendo que, tras de las creencias personales, los pacientes se encuentran en situaciones de liminalidad que precisan, como mínimo, consuelo y esperanza). 
Figura 2

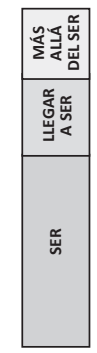

La modernidad, como buena heredera del positivismo, hizo un especial énfasis en aquel espacio del ser más concreto, más material, en el soma. Esa proyección le permitía analizar al hombre como objeto. Una comprensión holística, sin embargo, lo sitúa en un campo conceptual mayor, el hombre como persona (Figura. 3).

Figura 3

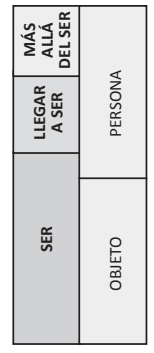

Bajo este encuadre, podemos situar las competencias específicas de los estudios de Medicina en América Latina desde lo puramente mecánico hasta lo más intangible del ser humano (Figura 4): del objeto a la persona. ${ }^{2}$

${ }^{2}$ Extraído de http://www.tuningal.org/es/areas-tematicas/medicina/compe-tencias, Internet, consultada en 22 agosto 2011. 
Víctor M. Armenteros

Figura 4

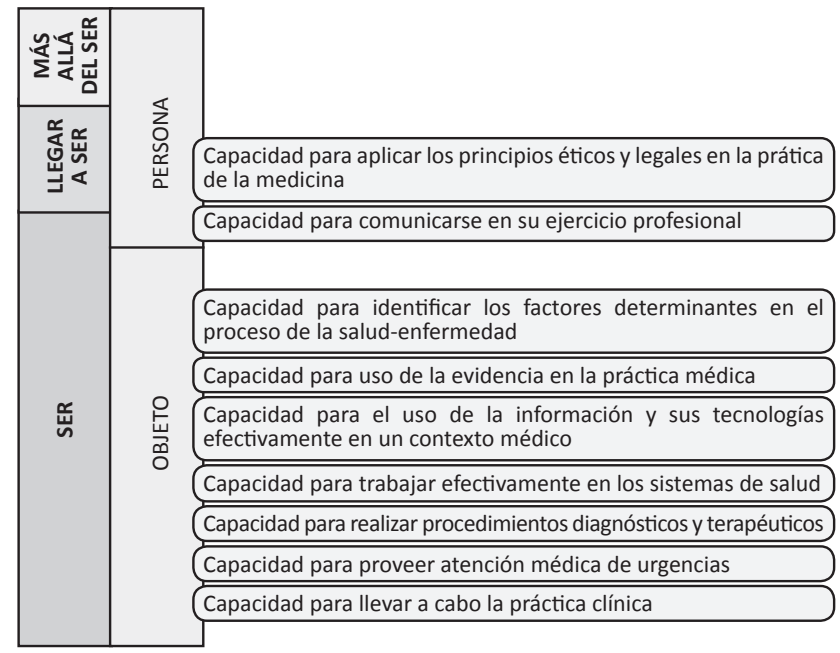

En el área del ser como objeto se puede incluir la práctica clínica (anamnesis, examen físico y mental, diagnóstico y tratamiento o procedimiento) y la estructura y función de los servicios de salud. En el área del ser como persona, usualmente clasificado como profesionalidad, los procesos comunicativos y la aplicación de principios éticos y legales.

No se consideran de forma explícita, sin embargo, las competencias del "llegar a ser" y del "más allá del ser". Hay, como mínimo, tres cuestiones a considerar sobre el "llegar a ser" que afectan intensamente al ser humano posmoderno: a) sobre el dolor, b) sobre la felicidad y c) sobre la realidad. Una, al menos, del "más allá del ser" que desde el origen del hombre se ha establecido como un universal: sobre la muerte (Figura 5). ${ }^{3}$

\footnotetext{
${ }^{3}$ Como afirma Zygmunt Bauman: "El 'miedo original', el miedo a la muerte, es un temor innato y endémico que todos los seres humanos compartimos, por lo que parece, con el resto de animales, debido al instinto de supervivencia programado en el transcurso de la evolución en todas las especies animales (o, al menos, en aquellas que sobrevivieron lo suficiente como para dejar rastros registrables de su existencia). Pero solo nosotros, los seres humanos, conocemos la inexorabilidad de la muerte y nos enfrentamos, por tanto, a la imponente tarea de sobrevivir a la adquisición de tal conciencia, es decir, a la tarea de vivir con (y pese a) la constancia que tenemos el carácter ineludible de la muerte". Zygmunt Bauman, Miedo líquido: la sociedad contemporánea y sus temores ( Barcelona: Paidós, 2007), 46.
} 
Figura 5

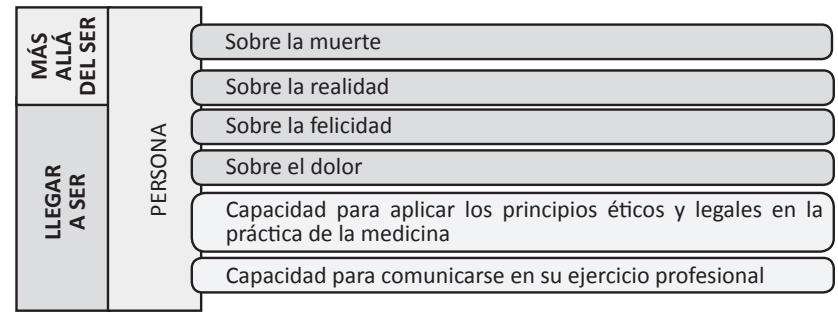

\section{El ser como objeto}

\section{Capacidad para realizar procedimientos diagnósticos y terapéuticos - Capacidad para trabajar efectivamente en los sistemas de salud}

La tarjeta de crédito es a la sociedad posmoderna lo que la libreta de ahorro fue a la moderna (Díaz, 2009 p.22). El consumo ha superado las normas de la necesidad para galopar sobre los lomos del impulso desbocado. Tal y como comenta Quijano (2008, p. 186):

El médico se imbuía desde sus estudios preliminares de lo difícil de su profesión, de la necesidad de continuar sus estudios y preparación toda su vida, que la satisfacción íntima de llegar a un diagnóstico acertado y ver que su tratamiento era exitoso, era el mejor pago por su esfuerzo-conducta. Desde estudiante sabía que, como dice Paulina Rivero, tenía dos deberes, aprender medicina y aprender a ser médico, que su profesión es de servicio y que para ejercerla, debía tener empatía con el enfermo, amor al prójimo y generosidad material y espiritual. Pero en la actualidad es común encontrar que hay un espíritu mezquino, primero se piensa en lo que dejará su actuación y en que -como la vida no tiene precio-, todo gasto del enfermo está justificado y por ello ordena estudios de laboratorio y gabinete superfluos o innecesarios, interna al paciente en un hospital (pues es más cómodo que verlo en su domicilio) y enfoca su desempeño como un negocio que debe ser redituable.

El consumismo proyecta al ser humano sobre el "tener" $y$, indefectiblemente, sobre el mundo de las cosas. El anhelo de poseer (realizando el énfasis en "anhelo" más que en "poseer") deviene en la cosificación de las personas. Dicha plataforma desnaturaliza, por tanto, la esencia misma de la práctica médica. Utilitarismo, uso, industria farmacéutica, servicios especiales, seguros médicos son visualizaciones de realidades que deterioran la imagen del cuerpo médico y, por ende, de la relación médico-paciente. 
Se plantea, en contraposición a la propuesta posmoderna de "consumo", el concepto de "sostenibilidad". Al igual que en la ecología global, surge por vía negativa y con condición de solución de urgencia. Es imperiosa la necesidad de equilibrar las expectativas económicas personales con la necesidad de una medicina que mejore al hombre, incluyendo al mismo actor de dicha medicina. Sostenibilidad implica una ocasión al análisis de lo realmente preciso y al beatus ille interior. En la ecología, reciclado es una segunda oportunidad a los materiales; en la medicina sostenible, atención al paciente es una segunda oportunidad a la persona. Trabajar efectivamente en los sistemas de salud tiene que ver tanto con eficiencia como con empatía. La pura eficiencia puede conducir y, posiblemente, esté conduciendo a la paradoja de Jevons. Peor sería que superásemos, si no sabemos parar a tiempo, un Óptimo de Pareto.

En una dinámica dialógica propondríamos las siguientes preguntas:

a. Como capital natural.

¿Qué espero de la práctica de la medicina? ¿Mejoran tales expectativas mi calidad de vida? ¿Mejoran las de los demás?

b. Como capital natural degradado.

¿En qué me afecta profesionalmente el consumo? ¿Cuándo tengo tendencia a la cosificación?

c. Como búsqueda de soluciones.

¿Dónde se halla el equilibrio entre mis necesidades y las de los otros? ¿Cómo puedo gestionar mis competencias para generar un desempeño de calidad?

d. Como realización de compromisos.

¿A qué estoy dispuesto a renunciar por el desempeño esencial de mi profesión? ¿Cuánto me importan las personas? ¿Qué deseo aportar a los demás?

\section{Capacidad para el uso de la información y sus tecnologías efectivamente en un contexto médico}

En la posmodernidad la ciencia ha sufrido un notable deterioro, todo lo contrario que la tecnología. Díaz $(2009$, p.22) lo clarifica con las siguientes palabras:

El gran relato pierde credibilidad. La ciencia entra en crisis interna y externa. Se conmueven las leyes inmutables y deterministas sobre las que la ciencia pretendió apoyarse, por una parte, y se deteriora su imagen de salvadora 
absoluta de la sociedad, por la otra. Ambos conflictos se tocan en un punto: la tecnología. El conflicto externo se origina en la comprobación de que la ciencia, a través de sus aplicaciones tecnológicas, produce bienestar, pero también produce destrucción.

El empleo de la tecnología como instrumento para el diagnóstico e intervención médicas son loables. El problema que puede detectarse está más vinculado con la fragmentación del hombre. Bauman (2011, pp. 222-223) lo expresa con notable precisión cuando afirma:

Al igual que todo lo demás, los seres humanos modernos son objetos tecnológicos. $Y$ al igual que todo lo demás, han sido analizados -divididos en fragmentos- y luego sintetizados de maneras nuevas: como arreglos o solo colecciones de fragmentos. Y éste no fue un logro que se diera de una buena vez: el ensamblado y desensamblado se suceden continuamente y desde tiempo atrás se autoimpulsan, ya que la síntesis, que no es sino otro arreglo de fragmentos, no puede ser una invitación constante -una presión todopoderosa- para realizar un análisis novedoso y mejorado. "Cada técnica humana", afirma Ellul, "está circunscrita a una esfera de acción, y ninguna abarca al hombre en su totalidad". Posiblemente las técnicas se dirijan al hígado y, entonces, cualquier cosa que les suceda a los riñones no será sino un efecto secundario. $O$ posiblemente estén dirigidos a obtener más seguridad en sí y lo que suceda con la exención de los deberes paternos es únicamente el efecto colateral. Con los lentes de la tecnología los seres humanos siempre parecen como la conjunción de un "problema" muy enfocado y un área vasta, aunque opaca, de efectos colaterales desenfocados.

Se debe potenciar la visión global de la persona, detectar al hombre tras el conjunto de análisis o datos. La tecnología debe ejercer más como instrumento ("Aquello que sirve de medio para hacer algo o conseguir un fin") en lugar de como máquina (en el sentido de "intervención de lo maravilloso"). La magnificación de la tecnología, además, genera expectativas cuasimágicas que se ven troncadas por la temporalidad de "lo último" o la constatación de la finitud de los objetos.

Se plantea, en contraposición a la propuesta posmoderna de "deificación de la tecnología", el concepto de "cosificación del instrumento" y "descosificación de la persona". Y con ello las preguntas:

a. Cosificación del instrumento.

¿Para qué me sirve este instrumento? ¿Cuáles son sus límites? ¿Qué parte de la globalidad del paciente me presenta? ¿Cómo puedo compensar sus carencias de información? 
Víctor M. Armenteros

b. Descosificación de la persona.

¿Cuáles son los valores del paciente? ¿Qué es lo que realmente quiere? ¿Qué es lo mejor para esa persona? ¿En qué sentidos se encuentra vulnerable? ¿Cómo puedo respetarlo de forma más adecuada?

\section{El ser como persona}

\section{Capacidad para comunicarse en su ejercicio profesional}

Vivimos tiempos de conectividad. La incorporación de Internet en nuestras vidas ha propiciado exponencialmente los medios de comunicación y los espacios de interrelación se han modificado; cafés, plazas y salas se han trocado en foros, redes sociales y streaming. La facilidad de conexión, sin embargo, también se ha convertido en facilidad para la desconexión. ¿Por qué se recurre más al mensaje electrónico que al correo electrónico? (Bauman, 2011. pp. 190-191). Precisamente por eso, porque propicia una desconexión más ágil. Tendríamos que preguntarnos juntamente con García (2008, p. 101):

¿La comunicación hace que los sujetos creen lazos de comunidad?, ¿y qué es hacer comunidad y lo que significan los conceptos de comunidad y de común? Si alguien que yo no conozca me manda un comunicado escrito, una propaganda, por ejemplo, y yo la leo, ¿̇eso significa que ese desconocido se comunicó conmigo? $\mathrm{O}$, si alguien que yo conozco y que sea mi amigo, incluso, me envía un e-mail, y yo lo respondo, ¿nosotros establecimos una "relación" comunicacional? Si la respuesta es sí, entonces solo la comunicación podría suceder entre sujetos que se conozcan, o como mínimo que se reconozcan,...

En la efervescencia de Facebook (red social) o Twitter (red de contenido) hemos de reflexionar sobre una comunicación de calidad. Obviamente la relación médico-paciente debe situarse en el ámbito de una comunicación interrelacionada y estableciendo una relación de ayuda. Como indica, con cierto aire literario, Bermejo (1998, p.40):

Se escucha haciendo silencio dentro de sí, evitando todo juicio sobre el otro y sobre lo que dice, evitando dejarse llevar por prejuicios, liberándose de la obsesión por uno mismo y haciendo espacio al otro. Evitando las distracciones y atentos al paralenguaje, es decir, al tono de voz, las pausas, la velocidad... Se escucha con los oídos atentos a los sentimientos.

El que escucha con el corazón se convierte en instrumento de curación, porque da espacio a los otros para abrirse con creciente confianza y libertad y les permite sentirse comprendidos y afirmados. Ayudar a curarse no significa solo suministrar fármacos, sino también, cuando es necesario, ayudar a 
reinventarse a sí mismo, a ser protagonista de la propia "película", sin caer en la tentación de la renuncia o de la actitud pasiva.

Se plantea, en contraposición a la propuesta posmoderna de "comunicación frágil", el concepto de "comunicación en proximidad". Este tipo de comunicación personalista se caracteriza porque es interactiva (ambos se orientan hacia la sanación, cuidado y curación), personal (intercambio orgánico en el que intervienen la razón, la voluntad y la afectividad), dinámica (el consentimiento ilustrado funciona como proceso educativo), comprometedora (coherencia e integridad al aplicar los principios morales y clínicos) y comunitaria (justa solidaridad con la comunidad institucional y social) (Lugo, 2006. pp. 11-12). Entonces, las preguntas catalizadoras podrían ser:

a. Naturaleza de la comunicación

La comunicación que estoy proponiendo, ¿sostiene a la persona en momentos de crisis?, ¿le ayuda a salir del estado de angustia, superar la culpa, evitar el aislamiento o la alienación?, ¿la conduce a su propia realización? (Bermejo, s/f)

b. Persistencia de la comunicación

¿Qué impacto sobre mi quehacer comunicativo tiene el eficientismo? ¿Espero resultados inmediatos? ¿Qué impacto sobre mi quehacer comunicativo tiene el tiempo? ¿Me molesta dilatar una interrelación? ¿Cómo afecta mi interés por el paciente en la persistencia del acto comunicativo?

\section{Capacidad para aplicar los principios éticos y legales en la práctica de la medicina}

Sin lugar a dudas, uno de los espacios donde más ha impactado la posmodernidad recala en la percepción de la ética. No tiene ningún desperdicio la definición y comentario de Díaz (2009, p.73):

La ética moderna ha sido fagocitada por el marketing. Este cambio de dispositivo ético-social se está generando a partir de la mitad del siglo XX. Denomino "posética" a esta nueva relación entre el hombre y los valores. Los elementos éticos formales siguen siendo los mismos. Se trata de los valores, de lo que está bien y de lo que está mal. Sin embargo, hay un cambio fundamental: el tipo de interrogantes que el sujeto se plantea respecto de su acción moral. La modernidad se preguntaba acerca de lo necesario (categórico). En cambio, la posmodernidad se pregunta acerca de lo conveniente (hipotético). 
Víctor M. Armenteros

En la modernidad había que preguntar "¿Qué debo hacer?". La respuesta es categórica: actuar según el deber. Lo instrumental debía someterse a lo categórico. Había que cumplir con el deber por el deber mismo, sin medir sus consecuencias. En cambio, en la posmodernidad se pregunta acerca de lo instrumental: “¿Qué me conviene hacer?”. La respuesta es hipotética: actuar según lo que se desea obtener. Además, el deber le dejó paso al derecho. Cuando se tenían deberes, había que cumplirlos según los valores consagrados por una racionalidad universal. Cuando se alegan derechos, el sujeto debe ser responsable del uso que haga de ellos.

La ética en la medicina, superando la tendencia de la posmodernidad, debe asociarse con la finalidad de ésta: la promesa de proveer de ayuda competente (la restauración o mejora de la salud, curar la enfermedad, ayudar y cuidar al paciente cuando exista dolor, molestia o discapacidad). Dicha finalidad genera, tal y como lo plantean Pellegrino y Thomasma desde su "beneficencia en confianza", algunas virtudes a considerar: fidelidad a la confianza, compasión, justicia, fortaleza, templanza, integridad y modestia (Pellegrino y Thomasma, 1993; Brussino, 2001. pp. 43-58). Nombres antiguos para necesidades universales.

Se plantea, en contraposición a la propuesta posmoderna de "relativización", el concepto de "identidad". Cada vez se solapan más los campos semánticos de "identidad" e "identificación". La ética en medicina debiera ir más allá del hecho de "reconocer" lo que le podría ser propio para adentrarse en su esencia, forma y valor. Derivadas de esta dinámica surgen, por tanto, algunas cuestiones:

a. Sobre la relativización.

¿Puede existir el ser humano sin metanarrativas? ¿Se pueden cuestionar los principios de "no maleficiencia", "beneficencia", "autonomía" y "justicia"? ¿Se percibe como real la diferencia entre "ética" y "deontología"?

b. Sobre la identidad.

¿Tengo un referente concreto en el cual apoyarme cuando existen dudas? ¿Cuáles son los posibles escenarios ante dilemas de confidencialidad, eutanasia, aborto, intrusismo, mala praxis política? ¿Sabría definir mi identidad como médico?

\section{Llegar a ser persona}

\section{Sobre el dolor}

Reflexionar sobre el aprendizaje acerca o en el dolor es contranatural para con la mentalidad posmoderna. El dolor es ruido frente a la salud que es 
silencio, todo funciona perfectamente mientras todo esté aplacado. En una especie de alejamiento del dolor orgánico se generan multitud de propuestas porque "el dolor posmoderno, si seguimos el esquema de Lyotard, sería un dolor que no puede insertarse en una metanarración única y abarcadora, en un único sistema de explicaciones. Es un dolor que ha recuperado o redescubierto sus voces múltiples" (Morris, 1996). Se expresa a la perfección en la cita de Mainetti (2011):

Pero junto a la algología científica existe, existe una algología filosófica, una visión especulativa o reflexiva sobre el dolor, pues éste no se reduce a la inteligencia técnica e implica un acto de aprehensión espiritual. La algodialéctica contrapone un modelo humanista y otro positivista en torno, fundamentalmente, a la naturaleza finalista o no, fisiológica o patológica del dolor. La algodicea cuestiona la justificación del dolor a través de figuras tales como el castigo (el inglés pain proviene del latín poena), la prueba, el azar o el reto. El algomisterio (mysterium doloris) apunta, más allá del alma y del cuerpo, a la ontogénesis de esa relación no objetivable, al dolor como morada del hombre y poder del lógos (algos = alego) de juntar en la diferencia. La algopoética registra dolor e imaginación como antípodas intencionales (conciencia sin objeto y objeto sin conciencia) y la base invisible de todo acto de creación cultural, de modo que la humanitas mora en el sufrimiento, éste es la "moral", "nuestro dolorido sentir".

El hecho de reconocer, tratar e interpretar el dolor es un reto para la medicina actual. El esfuerzo de ayudar al paciente a reconocer e interpretar el dolor es un vacío que los cuidados paliativos no alcanzarán a cubrir porque precisa de la participación del mismo paciente.

La función formativa del médico en el tema del dolor es crucial. Debe ayudar al paciente a hacerse cargo de éste de forma personal. Así se producirán modificaciones en los hábitos y conductas que aportarán plataformas más sanas y constructivas. Se debe aprender a resolver los problemas mucho antes que a hacer que se acalle el dolor. Como afirma Morris (1996, p. 332):

No hay la menor duda de que vamos a fracasar como cultura si continuamos negando o ignorando el dolor como si lo pudiéramos silenciar bajo una montaña de píldoras. Eso no resulta, es evidente... El placer llega y se marcha, a veces en un solo instante; pero el dolor tiene el poder suficiente para quedarse. El dolor crónico cambia inevitablemente el mundo que habitamos, como un invierno permanente. La medicina sola no puede resolver todas las preguntas que plantea el dolor. El error está en pedir a los médicos que asuman el peso completo de una situación que transciende con mucho los límites de la práctica de la medicina. 
Víctor M. Armenteros

Se plantea, en contraposición a la propuesta posmoderna del "placer constante" y del "silenciamiento" del dolor, el concepto de aprendizaje de la "resiliencia". Las preguntas pueden dar cabida a:

a. Fortalecimiento de la resiliencia.

¿Cómo puede mi paciente tratarse con dignidad, aprender a equivocarse y aceptar sus responsabilidades? ¿Cómo puede cambiar o cambiarse ante lo que no le satisface? ¿Cómo puede pensar y crecer a pesar del dolor?

b. Potenciar la esperanza.

¿Cuál es el horizonte de mi paciente? ¿Qué implica eso? ¿En qué plataforma de transcendencia se encuentra? ¿Cómo puede ese escenario permitirle que se recupere anímicamente? ¿Cuál es mi posición e influencia en estas circunstancias?

\section{Sobre la felicidad}

En un extenso capítulo sobre "la (in)felicidad de los placeres inciertos", Bauman (2011, p. 190) propone:

"Surfear" es una palabra que se ha vuelto popular recientemente, y que captura de manera cabal la nueva mentalidad del nuevo mundo de la incertidumbre. Se surfea más rápido de lo que se nada y, además, no es necesario sumergirse en la sustancia fluida por la cual (o sobre la cual, si uno es un hábil navegante) uno se mueve. Cuando se surfea, el contacto con la sustancia nunca va más allá del nivel de la piel, y basta con una toalla para quitarse del cuerpo la potencial humedad... Hoy en día, toda profundidad (y considérense avisados: lo profundo comienza justo debajo de la superficie) tiene una apariencia traicionera. La superficie es el único espacio que promete una relativa seguridad, no la ausencia del peligro, claro está, pero al menos la esperanza de que podrá huir antes de que éste nos golpee. Moverse bajo la superficie o ser atado al suelo, es buscarse problemas.

La posmodernidad se ha desencantado del pasado de la premodernidad y del futuro de la modernidad y se ha instalado en el presente. En un presente tan breve como el instante. La persona posmoderna no está tan interesada en el "hacer" como en el "gustar", se aparta del "tener" o "ser" para disfrutar del "usar". Es por ello que los modelos de felicidad que proponen son a corto plazo, productos del deseo del consumo más que del mismo consumo en sí. 
Pero ésta no es la condición del hombre. La naturaleza del ser humano no puede ser anestesiada por el inmovilismo del pensamiento único, sin reacción posible de los ideólogos del marketing. El médico, actor de notable influencia en el desarrollo de la sociedad debe no solo enseñar a cómo ser más sano sino instruir en el arte de vivir con equilibrio. En este sentido, las palabras de Rojas (2000, p. 52) expresan un exquisito sentido común:

Poner al bienestar y al placer como metas absolutas y decisivas de la conducta es un grave error, ya que la mejor de las travesías personales está surcada de problemas, luchas fracasos de distinto signo y por supuesto, retrocesos en la dirección de propio camino. Para mucha gente la felicidad queda reducida en última instancia a bienestar, nivel de vida, economía saneada y, por supuesto, salud. Otros planteamientos quedan fuera de ese espectro.

El camino de la felicidad pasa por haber ido resolviendo el fondo conflictivo que se hospeda dentro de nosotros. A medida que vamos descubriendo la complejidad de la existencia, nos damos cuenta que la felicidad no depende de la realidad sino de la interpretación de la realidad que uno hace. Nuestra travesía personal no puede ser como un barco sin rumbo dejado de la mano de Dios. Por eso es importante saber lo que uno quiere y hacia dónde va, y qué es lo que persigue. Si los sentimientos son intermediarios entre los instintos y la razón, la felicidad es la suma y compendio de la vida auténtica.

Se plantea, en contraposición a la propuesta posmoderna de "felicidad superficial", el concepto de aprendizaje del sentido común en la búsqueda de una "felicidad razonable". Si, como indica Eduard Punset, la FELICIDAD $=E(M+B+P) / R+C$, cabe preguntarse:

a. Sobre los factores significativos.

¿Cómo puedo enseñar a mi paciente que la sensación de felicidad suele percibirse más al principio y al final de un proyecto? ¿Cómo puede captar que en la atención y mantenimiento del detalle hay mayor satisfacción; que la búsqueda es sumamente relevante y debe ser disfrutada; que las expectativas deben responder al sentido común; que se deben potenciar y apreciar las relaciones personales?

b. Sobre los factores reductores y hereditarios.

¿Cómo puedo enseñar a mis pacientes a tener miedo en sus proporciones adecuadas? ¿Cómo puede captar que no condice tanto la realidad como la interpretación de ésta? 


\section{Sobre la realidad}

La posmodernidad ha trocado realidad por virtualidad. La información es excesiva e impacta y arrolla con tal magnitud que provoca, forzosamente, la desconexión. El escapismo, la ficción, el brillo de los artificios se impone ante la tortuosa posibilidad de ser agentes vicarios de tantas irregularidades que nos circundan. La saturación de noticias produce insensibilidad y se prefiere la estampa, estática y satisfecha, de la Mildred bradburiana a la imagen comprometida de Kevin Carter en el sur de Sudán. El síndrome de Jabberwocky se contornea en la realidad posmoderna ofertando imágenes photosopeadas como si pertenecieran a la vida misma. La virtualidad es el opiáceo de las masas.

Debe haber un giro copernicano sobre esta tendencia.

Cualquiera que tenga planeado hacer algo para cambiar el mundo, o para mejorar las condiciones de la vida humana, sumando algo a las posesiones de los hombres o alterando el modo en que se las usa, hará bien en intentar otra cosa. Concentrar esfuerzos y esperanzas en las herramientas ortodoxas, irremediablemente locales, de la acción conjunta sería, según parece, un derroche de tiempo y energías (Bauman, 2011. p. 284).

El médico puede y debe ser agente de cambio ante el inmovilismo social. La solidaridad, no confundirse con el turismo asistencial, surge del entorno de la medicina de forma natural. Potenciar en el estudiante de las ciencias médicas la solidaridad no solo aporta soluciones a las realidades de los menos favorecidos, sino que fortalece la razón de ser de la profesión. El desencanto debe dejar de ampararse en la virtualidad para generar acción por medio de propuestas en solidaridad. Hacer el bien es una práctica que potencia la sostenibilidad, la descodificación, la proximidad, la identidad, la resiliencia, el sentido común y, por supuesto, la solidaridad (Figura. 6).

No existen preguntas en nuestra tertulia dialógica a la realidad sino acciones para mejorarla. 
Figura 6

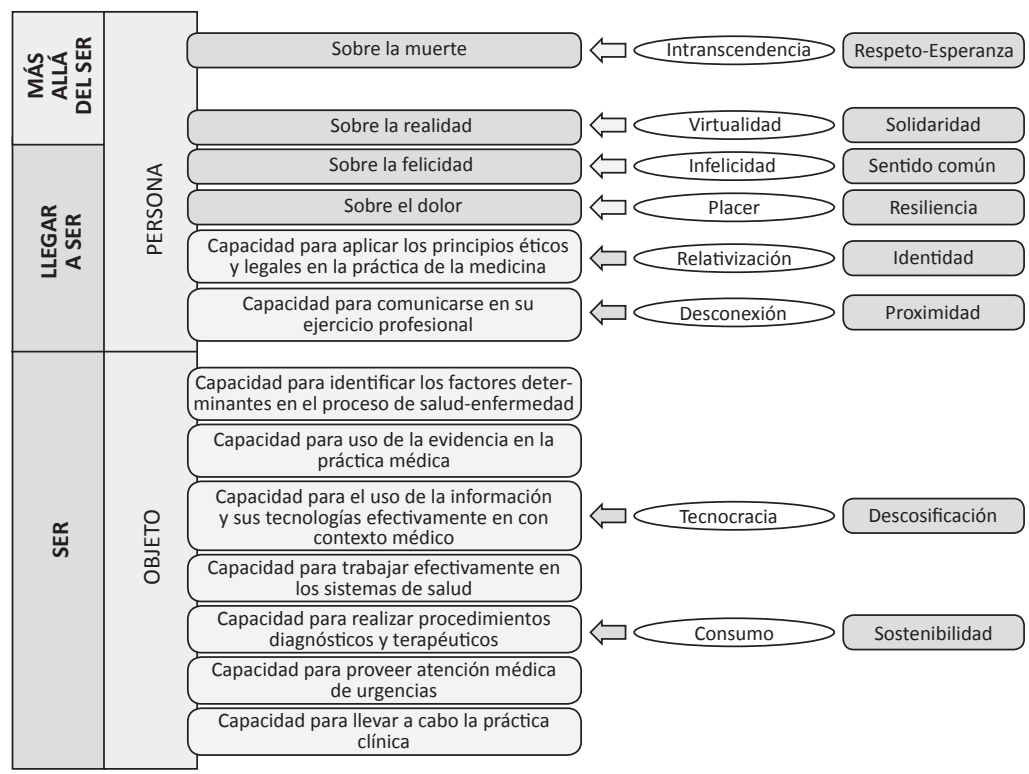

\section{Más allá del ser persona}

\section{Sobre la muerte}

El único universal que no puede sortear la posmodernidad es la muerte. Esa tensión entre la razón (modernidad), la banalización (posmodernidad) y la fe (¿premodernidad?) se colapsa justo antes de que el último hálito de vida abandone a la persona. No hay análisis empírico de lo inexperimentado e inobservable. No hay intrascendencia ante lo no transcendido. Hay, sin embargo, creencia para el creyente.

¿Qué desempeño debe tener el médico ante las diferentes cosmovisiones? ¿Neutralidad? ¿Tolerancia? ¿Hacerse a un lado cuando aparece el capellán para no incurrir en interferencias? ¿No le concierne nada sobre este asunto? La creencia (sea religión, desligión o espiritualidad) se ha situado en el marco de la vida privada pero, ¿no tiene la relación médicopaciente un alto componente de privacidad?

La propuesta de la posmodernidad es la banalización. En palabras de Bauman (2011, p. 198): 
Víctor M. Armenteros

Se oculta la muerte cerca del hogar, mientras que la muerte como dilema humano universal, la muerte de los otros anónimos y "generalizados", se expone descaradamente, se convierte en un interminable espectáculo callejero que, habiendo dejado de ser un acontecimiento sagrado o carnavalesco, es tan solo uno más entre los muchos de la parafernalia de la vida diaria. De esa forma, la muerte banalizada se ha convertido en algo demasiado familiar para ser notado o para despertar emociones profundas. Es lo "habitual", demasiado común para ser dramático y ciertamente demasiado común para dramatizarlo. Su horror se exorciza mediante su omnipresencia, se convierte en ausente mediante el exceso de visibilidad, se convierte en insignificante por ser ubicuo, se silencia mediante un ruido ensordecedor. $Y$ mientras la muerte se va desvaneciendo y finalmente muriendo mediante la banalización, también se desvanece la inversión emocional y volitiva en el anhelo de derrotarla... Es como si la multitud hubiese sido subrepticia pero sistemáticamente instruida para que no desee lo que es improbable conseguir a ningún precio; a no desear la vida eterna cuando -sí- se convierte en algo factible.

Se plantea, en contraposición a la propuesta posmoderna de "intranscendencia", el concepto de "respeto" y "esperanza". La tolerancia acarrea desazón, el respeto implica consideración. La intranscendencia acarrea ilusión, el respeto implica esperanza. Las investigaciones en neurociencia y espiritualidad aportan fundamento a tal respeto. ${ }^{4}$

En este momento de la posmodernidad quizá sea demasiado transgresor hacer preguntas públicas sobre la transcendencia y deban remitirse a la intimidad de nuestras creencias o increencias. Permítaseme, sin embargo, proponer el comentario de un pensador del "más acá" y del "más allá", Moltmann (1996, p. 436):

Este mundo no es el cielo de la realización de sí mismo, como se afirmaba en el idealismo. Este mundo no es el infierno de la alienación de sí mismo, como se dice en la literatura romántica y existencialista. El mundo no está todavía listo, sino que es concebido como situado en la historia. Por ello es el mundo de lo posible, en el cual se puede servir a la verdad, a la justicia y a la paz futuras prometidas. Es el tiempo de la diáspora, de la siembra para la esperanza, de la entrega y del sacrificio, pues este tiempo se encuentra en el horizonte de un nuevo futuro.

Entre el mito, generado por una modernidad de panegíricos, y el mate, de una posmodernidad de múltiples sociabilizaciones, se encuentra,

${ }^{4}$ N. Azari, H. Koenig, B. Puri, A. Newberg, R. Sudsuang, R. Schneider, H. Prigerson, B. Uchino, D. McClelland, $K$. Cha son algunos de los investigadores que han constatado la influencia de la espiritualidad en procesos de mejora de la enfermedad y prolongación de la salud. 
hoy, el desempeño de la actividad médica. Tiempo de reflexiones y de acciones, tiempo de recordar la esencia de la profesión y, adheridos una vez más a la esperanza, decir: "Pronto vuelvo".

Aunque solo sea a modo de apostilla, unas palabras de compromiso. No hay lugar a dudas de que el ser humano supera con mucho a la máquina (modernidad) y también al periférico (posmodernidad). Es, por tanto, tiempo de que paremos la mecánica de resultados inmediatos y de horarios de precisión inalcanzable; que aflojemos con las descargas descontroladas de información y de expectativas tecnoadictivas, para volver a recomponer nuestro concepto de persona y de interrelación. Así lo pide el médico aquejado por el "burnout" o preso de desconfianzas implícitas. Así lo pide el paciente como ser sintiente y sentiente. Así lo pide el sentido común, competencia elemental y equilibradora de profesión y vida.

Víctor M. Armenteros Universidad Adventista del Plata email: mizpahve@gmail.com

Recibido: 09 de Agosto de 2012 Aceptado: 21 de Octubre de 2012

\section{Referencias}

Bauman, Z. (2007). Miedo líquido: la sociedad contemporánea y sus temores. Barcelona: Paidós.

Bauman, Z. (2011). Ética posmoderna: en busca de una moralidad en el mundo contemporáneo. Buenos Aires: Siglo XXI.

Bauman, Z. (1997). La posmodernidad y sus descontentos. Madrid: Akal, 1997), 198.

Bauman, Z. (2011). La sociedad sitiada. Buenos Aires: Fondo de Cultura Económica.

Bermejo, J. (1998). Apuntes de relación de ayuda. Santander: Sal Terrae.

Brussino, S. (2001). Ética de las virtudes y medicina (II). Tópicos 008-009.

Díaz, E. (2009). Posmodernidad, 4a ed. Buenos Aires: Biblos. 


\section{Víctor M. Armenteros}

Díaz, M. (2006). Una visión de la postmodernidad: las medicinas alternativas y el cambio cultural, en el cambio social en España. Visiones y Retos de Futuro Sevilla: Centro de Estudios Andaluces.

Fielding, M. (2001). Students as Radical Agents of Change. Journal of Educational Change 2.

Fielding, M. (2004). Transformative Approaches to Student Voice: theoretical underpinnings, recalcitrant realities. British Educational Research Journal 30, 2

García, F. (2008). Comunicación y deconstrucción: el concepto de comunicación a partir de la obra de Jacques Derrida. Méjico: Universidad Iberoamericana.

García, F. (2011). Los últimos 50 años. Historia, presente y futuro de la Medicina; disponible en http://www.bioeticaweb.com/index2.php?option= com_content\&do_pdf=1\&id=9; Internet, consultada en 22 agosto 2011.

Lugo, E. (2006). Conferencia II. La ética del curar, cuidar y sanar. Visión integral del enfermar y de la enfermedad según el personalismo orgánico: responsabilidades compartidas entre enfermo y profesionales, Bioética Personalista. Córdoba, Argentina: Editorial Patris Argentina.

Mainetti, J. (2011). Medicina y humanitud: sufrir, envejecer, morir en el Primer Simposio Virtual de Dolor, Medicina Paliativa y Avances en Farmacología del Dolor. Extraído de http:// www.simposio-dolor.com.ar. Internet, consultada en 21 agosto 2011.

Martínez, J. (2011). Moral social y espiritualidad: una co(i)nspiración necesaria Santander: Sal Terrae.

Martínez, A. et al. (2008). Modelo de competencias del profesor de medicina. EDUC MEC 11, 3.

Moltmann, J. (1996). Teología de la esperanza. Salamanca: Sígueme Morris, D. (1996). La cultura del dolor. Santiago de Chile: Editorial Andrés Bello.

Pellegrino, E. y Thomasma, D. (1993). The Virtues in Medical Practic. New York: Oxford University Press.

Quijano, M. (2008). La postmodernidad y la medicina. Rev Fac Med UNAM 51.

Rojas, E. (2000). La felicidad razonable. ABC Saso, C. y Gómez, J. (2001). El giro dialógico de las ciencias sociales: hacia la comprensión de una metodología dialógica. Acciones e investigaciones sociales 12 .

Vélez, H. (2009). La medicina en la Postmodernidad, Rev CES Med 23,2. 